\title{
PROCEEDINGS OF THE CONFERENCE
}

\section{ON \\ NEW METHODS IN POSTGRADUATE MEDICAL TEACHING}

ORGANIZED BY

THE KENT POSTGRADUATE MEDICAL CENTRE AT CANTERBURY IN COLLABORATION WITH

\section{THE CONSULTING PHYSICIANS OF THE S.E. METROPOLITAN REGION}

\author{
(BRITISH POSTGRADUATE MEDICAL FEDERATION)
}

SUPPORTED BY PFIZER LTD.

Held at the Simon Langton Girls' School, Canterbury, on October 31st, 1964

\section{INTRODUCTION}

\author{
Sir George V. Allen, C.B.E., M.D., LL.D. \\ President, Kent Postgraduate Medical Centre at Canterbury
}

IT GIVES me great pleasure, on behalf of the Kent Postgraduate Medical Centre to welcome you. We are honoured because you have chosen Canterbury as the venue for this conference, and we are particularly pleased because the subject to be discussed is one of special importance to us at this time.

The Kent Postgraduate Medical Centre, established on 29th May, 1964, has two major functions-integration and dissemination. The most striking feature of today is the speed of change resulting from the applications of scientific and technological research. The individual is continually faced with the major problem of trying to keep in touch with the advances in knowledge not only in medicine, dental and veterinary surgery, but also in the relevant fields of the physical, biological and social sciences. There is also an urgent need for much closer integration because of the increasing fragmentation of knowledge into specialised compartments with the growing isolation of the various groups of specialists.
There is a need too for a better understanding of the social and economic structure of the community. A new society is emerging, a society with new attitudes, subjected to new pressures and with a new pattern of disease.

Any attempt to solve these problems will depend for its success on the effectiveness of the methods of communication.

Fortunately important developments have been taking place in recent years. Communication theory is a subject of intensive study and Cybernetics is rapidly becoming an important branch of science. Films, tape recordings and television are now being used in various ways and programmed teaching courses are available. The purpose of this conference is to study and discuss these new methods and in particular their uses and limitations. It is essential that these aids to communication should be understood and utilised fully whenever appropriate. Without them our efforts to keep in touch with the advances in knowledge may be severely handicapped. 